\title{
Hacia una antropología negativa benjaminiana
}

\section{Towards a Benjaminian Negative Anthropology}

\author{
Alexánder Hincapié García ${ }^{1}$ \\ Universidad de San Buenaventura Medellín (Colombia) \\ ORCID: https://orcid.org/0000-0001-6828-2786
}

Juan David Piñeres Sus ${ }^{2}$

Universidad de Antioquia (Colombia)

ORCID: https://orcid.org/0000-0003-1870-4113

Recibido: 12-04-2020

Aceptado: 22-06-2020

\section{Resumen}

Este trabajo establece una relación crítica entre los conceptos de memoria y experiencia en la obra de Walter Benjamin, como paso previo para exponer la filosofía negativa de la historia del mismo autor -concebida en términos de rememoración y redención-. Este referente conceptual es la base para una antropología negativa benjaminiana que rechaza la universalidad antropológica formal y el esfuerzo por imponer un ideal de ser humano que debe alcanzarse por todos los hombres.

Palabras-clave: Benjamin, memoria, experiencia, filosofía negativa, antropología negativa.

\footnotetext{
${ }^{1}$ (alexander.hincapie@usbmed.edu.co) Docente investigador. Entre sus recientes publicaciones se destacan los artículos: Los derechos humanos y el problema de la cárcel en Colombia: Una perspectiva de lectura genealógica. CES Derecho. y Construcción de paz y ciudadanía. Entre la indiferencia y la memoria. Perseitas. También editó junto a Emmauel Taub el libro De Benjamin a Marcuse. Lecturas en torno a Para una crítica de la violencia de Walter Benjamin (Fondo Editorial Bonaventuriano).

2 (juan.pineres@udea.edu.co) Docente investigador. Entre sus recientes publicaciones se destacan los artículos: Persuasión moral en el marco del posconflicto en Colombia: un estudio sobre la calidad de los argumentos y la experticia de la fuente. Acta Colombiana de Psicología y Civilización, culto y escritura en el desarrollo de la mente. Revista de Psicología Universidad de Antioquia. También contribuyó con un capítulo para el libro De Benjamin a Marcuse. Lecturas en torno a Para una crítica de la violencia de Walter Benjamin (Fondo Editorial Bonaventuriano).
} 


\begin{abstract}
This paper establishes a critical relationship between the concepts of memory and experience in the writings of Walter Benjamin, as a preliminary step to expose the negative philosophy of the same author-conceived in terms of remembrance and redemption. This conceptual framework is necessary to propose a Benjaminian negative anthropology that rejects formal anthropological universality and the effort to impose a human ideal that must be achieved by all human beings.
\end{abstract}

Keywords: Benjamin, memory, experience, negative philosophy, negative anthropology.

¿Qué es el tiempo? [...] El tiempo es activo, posee una naturaleza verbal, es "productivo".

¿Y qué produce? Produce el cambio.

(La Montaña Mágica, Thomas Mann, 2013 [1924], p. 498)

\title{
Introducción
}

"El origen es la meta". Con este enigmático epígrafe sacado de Worte in Versen I de Karl Kraus, Benjamin (2009a) introduce la tesis XIV del ensayo Sobre el concepto de historia. Löwy (2005) señala que este epígrafe tiene un doble sentido, tanto teológico como político. El sentido teológico se relaciona con el paraíso como origen. La redención-Erlösung-es un retorno. Pero, el origen al que denominamos, el paraíso, no es otra cosa que la sociedad sin clases conocida por la humanidad. El sentido político indica que la revolución mira al pasado; es decir, la política tiene una cita con los muertos, porque la justicia que reclamamos para nosotros, no puede ser ajena a la justicia que se debe a los hombres sacrificados en el pasado y que se siguen sacrificando al no quebrar ciclo repetitivo del olvido.

Podría decirse que la antropología negativa propuesta a partir de Benjamin, ejerce una crítica radical a todo tipo de amnistía histórica por la cual se declara que el pasado está superado y que, por lo mismo, la armonía entre los hombres tiene que ser la actualidad de nuestro presente. En nombre de un supuesto ideal de humanidad, se sacrifica infinidad de vidas que se juzgan exteriores a dicho ideal. Es por esto que la antropología negativa exige la rememoración -Eigendenken - y la redención de la humanidad entera. No solo rechaza el universalismo antropológico formal con el que se prescribe qué es el hombre y cuál es el tipo de humanidad que le corresponde, sino que también eleva la rememoración y la redención como criterios normativos sin los cuales toda ética está condenada a la ruina. 
El método de investigación utilizado en este trabajo es filosófico; así, la exposición misma va revelando el cómo se organizan los argumentos en función del problema planteado entre los conceptos extraídos de la filosofía de Benjamin y la antropología negativa que de ella deriva. Ahora bien, que el método de la filosofía sea la exposición, necesita una comparación importante. Mientras que en la forma como habitualmente se representa la relación entre el método y el objeto, el método es el camino a través del cual se busca y el objeto es, en cierta medida, engendrado por la misma voluntad de búsqueda por poseerlo, la verdad, como la concibe Benjamin, no es engendrada por el método y tampoco es una posesión. La verdad es exposición de sí misma y, de este modo, tal vez podamos decir que el método está en la exposición de la verdad que pertenece a las ideas. No puede ser una tenaza aplicada desde afuera para que la verdad se revele por la fuerza - el método sirve a la verdad en su exposición y no al contrario-.

La exposición de nuestros argumentos se concreta en tres partes. La primera se titula Memoria y experiencia: una exposición crítica, aquí planteamos que solo la memoria entendida como fuerza vinculante entre los hombres, puede actuar frente a la pérdida progresiva de posibilidades para la experiencia. En la segunda parte, La filosofia negativa de la historia: rememoración y redención, se establecen los términos de la filosofía negativa de Benjamin, a partir de la necesidad transformar nuestra relación con el pasado. Si el historiador asegura que este es objeto de la ciencia, el crítico inspirado en el materialismo histórico de Benjamin, sabe que el pasado es más que una acumulación de datos "ordenados". Este contiene los índices secretos que actualizan las deudas del hombre con el hombre. La tercera parte titulada: La antropología negativa como crítica al universalismo antropológico formal, permite sostener que de este universalismo no se deriva ninguna corrección de las deudas históricas con la humanidad entera. Al contrario, el universalismo antropológico formal es una amnistía histórica con la cual se declara que todas las deudas están saldadas y que el porvenir de la humanidad no puede ser otro que la armonía entre los hombres. Para finalizar, se concluye resaltando la importancia de la antropología negativa de Ulrich Sonnemann y su posible concordancia con una antropología negativa benjaminiana. Sin embargo, antes de Sonnemann, Benjamin ha demostrado que el buscar lo humano en el ideal, por fuerza, deriva en el empuje por corregirlo o sacrificarlo.

\section{Memoria y experiencia: una exposición crítica}

En su obra $A$ la recherche du temps perdu, Proust introduce un elemento que, según Benjamin (2001), contiene una crítica inmanente a la teoría de la memoria de Henri Bergson, para quien encarar la actualización intuitiva del 
flujo vital es un asunto de libre elección -en principio, dígase que los recuerdos son el núcleo de lo que Bergson denomina flujo vital-. Al respecto, cítese al autor: "L'intérêt d'un être vivant est de saisir dans une situation présente ce qui ressemble à une situation antérieure, puis d'en rappocher ce qui a précédé et surtout ce qui a suivi, a fin de profiter de son expérience passée" (Bergson, 1949, p. 272-273) ${ }^{3}$. Proust difiere del énfasis de Bergson en la libertad para elegir sobre los recuerdos $\mathrm{y}$, de forma paralela, realiza una precisión terminológica al convertir la memoria pura -mémoire pure- de la teoría bergsoniana en memoria involuntaria -mémoire involontaire-. Asimismo, Proust confronta estas dos clases de memoria. Aclaremos a qué se refieren la una y la otra. La memoria voluntaria se halla de manera arbitraria a disposición del intelecto, en consecuencia, está dispuesta a responder al llamado del hombre $-\mathrm{o}$ del ser viviente, como dirá Bergson-; ella es idéntica al "[...] recuerdo voluntario, del cual se puede decir que las informaciones que nos proporciona sobre el pasado no conservan nada de éste" (Benjamin, 2001, p. 9) 4 . Para Proust, el intelecto es inútil para una verdadera evocación del pasado; esto significa, ni más ni menos, que del azar depende la conquista de una imagen de sí mismo impregnada del pasado. Este no está al alcance del ser humano de manera intencional. Al contrario, Proust advierte que todo recuerdo así producido, es decir, evocado intencionalmente, no guarda relación con el pasado. Dicho de otro modo, si la experiencia significa la actualización del pasado, para Proust, solo por medio del azar es posible dicha actualización.

Benjamin, por su parte, no considera natural la dependencia del azar para que el pasado se inscriba en la experiencia; esto sería aceptar que los llamados intereses internos del hombre tienen un carácter privado y que solo a él pertenecen. Por el contrario, Benjamin introduce uno de los temas centrales de su ensayo Sobre algunos temas en Baudelaire, por no decir su tesis central, y que puede leerse como un diagnóstico de la modernidad: el que se considere que los intereses internos del hombre solo tienen un carácter privado, expresa la destrucción de las posibilidades para que los hechos externos -la memoria colectiva, por ejemplo-, participen de la experiencia-Erfahrung- ${ }^{5}$.

3 "El interés de un ser viviente es el de captar en una situación presente lo semejante a una situación anterior, para luego recuperar lo que le ha precedido y en especial lo que le ha seguido, para beneficiarse de su experiencia pasada" (traducción propuesta).

${ }^{4}$ Esta cita resulta clave para el argumento, en la medida en que señala que lo que separa la memoria involuntaria de la voluntaria es la arbitrariedad con la que esta última dispone del recuerdo. A continuación, se relaciona en alemán: “[...] willkürliche Erinnerung, und von ihr gilt, daß die Informationen, welche sie über das Verflossene erteilt, nichts von ihm aufbehalten" (Benjamin, 1974, p. 610).

5 ¿A qué hace referencia Benjamin con esto de que los intereses internos del hombre, en la forma de intereses privados, y la experiencia auténtica difieren? Estamos acostumbrados a pensar en la vivencia -Erlebnis - como experiencia —Erfahrung-. 'Mi vivencia es lo que me hace único', parecen decir, por ejemplo, distintas formas de la Lebensphilosophie y, actualmente, los defensores de la llamada investigación cualitativa. Contrario a ello, Benjamin sugiere que la experiencia auténtica, 
Es decir, considerar que los intereses internos del hombre pertenecen, de manera exclusiva, a su subjetividad, significa una reducción catastrófica de las posibilidades de la experiencia. Esta impresión será sostenida por Benjamin a lo largo de su obra. De hecho, si lo consideramos como la última instantánea de sus heterogéneas inquietudes intelectuales, en el Libro de los pasajes Benjamin (2016) sostiene que la ruina del hombre moderno es su progresivo hundimiento en la subjetividad. Para precisarlo de una vez, el hombre que se hunde en $s u$ subjetividad, lo hace disminuyendo o, incluso, sacrificando las posibilidades de la experiencia. Esto no puede interpretarse de otra manera diferente al de un acelerado proceso de catástrofe.

Los signos de la pérdida moderna de experiencia pueden verificarse. Como se muestra en El narrador, Benjamin (2011) tiene en mente a la prensa. Esta no procede con el objetivo de que los lectores apropien los acontecimientos informados de modo tal que se integren a la experiencia individual y colectiva. Al contrario, la prensa excluye la posibilidad de que los acontecimientos actúen sobre el lector. La borrasca informativa, la sucesión frenética de noticias sin elaboración alguna, actúa restringiendo la experiencia. La información no penetra en la tradición, no lo logra constituirse en contenido para la experiencia y tampoco estremecer los cuerpos. Con sus grandes tirajes, la prensa comunica, pero no permite que, en particular, de los acontecimientos informados florezcan narraciones desde la vida en común de los seres humanos, menos aún permite reavivar la experiencia individual y colectiva. Dicho de modo taxativo, la narración -o el relato impregnado de tradición- se sustituye por información y, a su vez, la sustitución de esta última por la sensación refleja de la información es "[...] la atrofia progresiva de la experiencia" (Benjamin, 2011, p. 10).

Entre otras cosas, la atrofia moderna de la experiencia está al lado de la pérdida de la posibilidad de narrar. A diferencia de la prensa, y en general de los medios técnicos de reproducción informativa, la narración no busca comunicar el en sí de lo sucedido, sino que ella encarna la vida misma del narrador. Este último se narra a sí mismo y narra la comunidad que hace posible la experiencia. Al modo de la huella de la mano sobre la vasija de arcilla, en lo narrado queda el signo del narrador. Usando la terminología proustiana, debemos decir que la memoria involuntaria conserva las huellas de la situación en la que se produjo, por tanto, "Donde hay experiencia en el sentido propio del término, ciertos contenidos del pasado individual entran en conjunción en la memoria con

aunque también es individual y subjetiva, no es privativa de cada quien —esta sería más bien una idea característica del pensamiento burgués individualista-. La experiencia auténtica hunde sus raíces en la tradición y en los relatos que la narran. En este punto, y para captar la exposición del argumento, es importante entonces retener la diferencia entre estos dos conceptos. De manera puntual, la vivencia - Erlebnis - es sumatoria, discurre como el día a día sin que se aprecie con detalle mayor diferencia. Entre tanto, la experiencia -Erfahrung - es lo que interrumpe la continuidad y el día a día, al relacionar lo individual con lo colectivo, es decir, al actualizar las fuerzas vinculantes y creadoras de la tradición. 
elementos del pasado colectivo" (Benjamin, 2001, p. 10). Esto significa que la memoria individual conserva la huella de la memoria colectiva. La separación entre lo interno y lo externo, o entre lo privado y lo colectivo, no representa una necesidad inevitable del conocimiento, sino una elección histórica burguesa, para salvaguardar una problemática idea de vida privada y vida pública, al servicio de una separación aséptica de las distintas esferas de la vida.

De lo anterior se desprende que la memoria involuntaria, cuya expresión se hace evidente en la tarea del narrador, difiere de la vivencia. Benjamin se apoya en la teoría psicoanalítica, aunque más específicamente en el trabajo de Reik que en el de Freud. Reik mantiene una distinción entre reminiscencia involuntaria y reminiscencia voluntaria. Su punto de vista sugiere que la memoria tiene por función proteger las impresiones y, con ellas, la experiencia, mientras que el recuerdo busca disolverlas. La memoria conserva mientras el recuerdo destruye. Utilizando otro modo predicativo, el intento de elaborar la experiencia mediante un recuerdo consciente constituye su destrucción. La memoria involuntaria no debe ser comparada con aquel proceso mediante el cual todo shock que asalta la consciencia se supera al precio de la ruina de la experiencia. Las palabras de Benjamin rezan: "Traducido a la terminología proustiana: sólo puede llegar a ser parte integrante de la mémoire involontaire aquello que no ha sido vivido expresa y conscientemente, en suma, aquello que no ha sido una 'experiencia vivida' " (Benjamin, 2001, p. 11). Cuando el shock es detenido por la consciencia, y elaborado a través de un intelecto entrenado para fabricar reflexiones, el acontecimiento que lo ocasiona adquiere el carácter de mera vivencia. De forma simultánea, y gracias a su incorporación inmediata al registro consciente del recuerdo, el acontecimiento queda esterilizado para toda experiencia posible.

Insístase en la relación entre reflexión y vivencia. Cuanto menos penetran los estímulos en la experiencia tanto más corresponden al concepto de vivencia. La peculiar función reflexiva de defensa respecto del shock es definida por Benjamin como la tarea de asignar al acontecimiento un puesto temporal exacto en la consciencia, pero a costa de su propio contenido de experiencia. Un puesto temporal exacto es justo el principal resultado de la reflexión; por su intermedio, el acontecimiento se convierte en una mera vivencia, un recuerdo disponible a voluntad. Por el contrario, cuando la reflexión falla en la defensa contra el shock involuntario, esto es, contra las sensaciones e impresiones que conllevan el sentimiento de sorpresa, se produce el espanto. Benjamin comenta que Baudelaire fija el elemento del espanto en una imagen cruda, a saber: "Habla de un duelo en el cual el artista, antes de sucumbir, grita de espanto. Tal duelo es el proceso mismo de la creación. Por lo tanto, Baudelaire ha puesto la experiencia del shock en el centro de su tarea artística" (Benjamin, 2001, p. 13). Podría decirse que el espanto retrata el rostro del alegórico; siguiendo 
a Buck-Morss (2001), en la imagen de la "inquietud petrificada" se halla la clave de la posición política del poeta lírico. En dicha imagen, que expresa un desasosiego incapaz de desarrollarse, se muestra una inversión con respecto a la época barroca. La alegoría mira al cadáver únicamente desde afuera; pero, Baudelaire, por su parte, se arriesga a mirarlo desde adentro. La posición del poeta que mira desde adentro podría leerse como una cualidad que Benjamin quiere ganar para la crítica del materialismo histórico. A diferencia de Hegel, Engels y Poe, la mirada de Baudelaire está comprometida con lo que ve. Mira a las masas ciudadanas - la forma característica de la existencia del hombre moderno-, desde adentro y no desde afuera.

El espanto expresa muy bien la posición paradójica asumida por Baudelaire frente a su propia época; de un lado, no queda duda de que es un hombre moderno; del otro, su sensibilidad estética se alimenta de la ausencia de experiencia sensorial característica de la ciudad moderna. En otras palabras, la modernidad es un estado de espanto, pero parece que no hay opciones para abandonarlo. También resulta paradójico el incomprensible éxito de la poesía de Baudelaire en una época en la cual la lírica ha dejado de ser importante. Mejor dicho, en su obra vemos la fusión entre pasado y presente. Por esta razón, Benjamin lo interpreta como una especie de detective involuntario y secretamente insatisfecho con la burguesía -clase social a la que pertenece-; las palabras de Benjamin citadas por Buck-Morss (2001, p. 204) advierten: "[...] al darle forma alegórica a lo moderno, expresaba aquello que los objetos de su mundo habían devenido aun cuando ésta no fuera su intención consciente, e incluso sin comprender los orígenes objetivos de su rango alegórico”.

Tal como es elaborada por Benjamin, de esta figura ambigua podemos rescatar una característica del crítico, a saber, él pertenece a la época hacia la cual dirige su arsenal. En el poeta hallamos una íntima relación entre el shock y el contacto con las grandes masas ciudadanas, que no forman ni una clase, ni un cuerpo colectivo articulado y estructurado. Las masas son la multitud amorfa constituida por los que deambulan y recorren las calles. A pesar de que no sirve de modelo para sus obras, la multitud se encuentra inscrita en la creación del poeta en calidad de figura secreta. Benjamin es enfático en afirmar que, con la ayuda de la imagen del esgrimista, en específico con los golpes que asesta, Baudelaire se abre camino entre la multitud. Así, el crítico es un esgrimista melancólico que dirige sus golpes en contra de la multitud que, gracias a su propio ritmo acelerado, ha perdido la experiencia de la tradición ${ }^{6}$. En tanto que

\footnotetext{
${ }^{6}$ Entre 1921 y 1922, Benjamin redacta una presentación de la revista Angelus Novus; allí define la crítica como aquello que cuida de los umbrales. Unos años más tarde, en El origen del Trauerspiel alemán, la define como la tortura de la obra de arte. Este movimiento del concepto, indica que su carácter no puede fijarse de una vez y para siempre. Probablemente, como el esgrimista, la crítica significa la toma estratégica de posición para proteger las bases que es necesario salvar y para observar mejor desde dónde actualizar el salto del tigre sobre el enemigo, por utilizar la misma expresión de Benjamin.
}

Araucaria. Revista Iberoamericana de Filosofia, Política, Humanidades y Relaciones Internacionales, año $23, \mathrm{n}^{\circ} 48$. Tercer cuatrimestre de 2021. Pp. 57-77. ISSN 1575-6823 e-ISSN 2340-2199 https://dx.doi.org/10.12795/araucaria.2021.i48.03 
moderno, él también es parte de la multitud -o, por necesidad, debe moverse en ella-; ahora bien, en el caso de Baudelaire también hablamos de "[...] la multitud espiritual de las palabras, de los fragmentos, de los comienzos de versos con los cuales el poeta libra en las calles abandonadas su lucha por la presa poética" (Benjamin, 2001, p. 15). El espanto captado por el poeta, no es el preámbulo a una nueva experiencia floreciente, a la inversa, es la visión de la progresiva muerte de la experiencia en la modernidad. Las masas ciudadanas -la multitud con la que combate el esgrimista melancólico-, están vacías de experiencia.

En este punto es interesante recuperar una interpretación sobre el concepto de experiencia. Molano (2014) sostiene que dicho concepto posee en Benjamin, al menos, tres vectores. El primero está dirigido hacia la recuperación de la vida sensorial capaz de disolver la conflictiva división entre sujeto y objeto. No hay conocimiento sin experiencia argumenta Kant; sin embargo, el aporte del filósofo de Königsberg coincide y confirma la experiencia de la ciencia moderna, es decir, privativa y limitada en su temporalidad. Es decir, la experiencia de la ciencia no se ocupa de las acuciosas preguntas que el hombre le plantea, sino del aumento del conocimiento. Su rigor aséptico evade que puedan formularse preguntas para las que no hay un atisbo de respuesta. Por eso mismo, la ciencia expulsa la teología y la metafísica -incluso al arte-, allende sus fronteras. Como señala el mismo Benjamin (2010a) en Sobre el programa de la filosofía venidera, necesitamos otra experiencia, una que actúe transformando nuestras relaciones con el conocimiento. El segundo vector tiene relación con el potencial mnémico y cognitivo de la experiencia, en la medida en que esta dispone de fuerzas capaces de vincular la memoria y el conocimiento como apertura a la tradición. Finalmente, el tercer vector baliza la reflexión en torno a las distintas formas de experiencias sedimentadas y el conflicto entre ellas. Para nosotros, más importante que las experiencias sedimentadas, son aquellas que el curso de la historia han sido frustradas y, con ello, la esperanza de la felicidad que albergaban.

En suma, la experiencia reclamada por Benjamin es una que, en su condición fragmentaria, es un shock. Para ilustrar esta afirmación apelemos a Franz Kafka. En una carta de 1907 dirigida a Oskar Pollak, Kafka (2018) escribe que necesitamos libros que nos estremezcan como un golpe en la cara; libros que sean el hacha que estalla en pedazos el gélido mar en nosotros. En otras palabras, los libros que hacen experiencia no son los que ofrecen un sentido reflexivo de la vida, sino aquellos que lo desgarran. En contraste, tan afanosamente buscada por las filosofías de la vida, la vivencia se acomoda rápidamente a los ritmos cambiantes de la modernidad y, por cierto, a su lógica de producción y utilidad. Ella no es más que la pantalla que, con ayuda de una dudosa reflexión, se defiende levantando sus muros en contra del shock 
producido por la vida moderna y por el avance de su propia catástrofe, esto es, la instalación automática de la economía de mercado, pero también la cada vez más visible conversión del ser humano moderno en máquina. En palabras de Benjamin: "La función peculiar de defensa respecto a los shocks puede definirse en definitiva como la tarea de asignar al acontecimiento, a costa de la integridad de su contenido, un exacto puesto temporal en la conciencia. Tal sería el resultado último y mayor de la reflexión. Esta convertiría al acontecimiento en una 'experiencia vivida' " (Benjamin, 2001, p. 13).

Debemos retener la imagen del shock o, más bien, señalar porqué es tan importante para el tipo de crítica que Benjamin dibuja a través de Baudelaire. Ese súbito espanto mantiene indefensos a los hombres modernos frente al ritmo frenético de la vida en la ciudad. Aunque también los mantiene alejados de la falsa concepción según la cual ellos pueden controlar racionalmente la memoria y la experiencia. Es decir, siguiendo lo ya dicho, la memoria es una fuerza vinculante entre los hombres y no solo una posesión subjetiva. Asimismo, la experiencia auténtica solo puede expresarse en un carácter fragmentario. Hasta aquí, la pregunta por la necesidad de una filosofía negativa de la historia ha sido planteada. El hombre moderno, al definirse solo a través de sus intereses internos, tiene obturado el vínculo con la memoria. A su vez, no puede comunicar experiencias porque justo la experiencia es lo que la modernidad le niega. No solo está adormecido por la frenética y acelerada percepción del tiempo que escamotea la memoria y desecha la experiencia, también su capacidad de respuesta crítica está debilitada frente las transformaciones sensoriales que la modernidad ha introducido en los cuerpos.

\section{La filosofía negativa de la historia: rememoración y redención}

Para Benjamin (2016, p. 473), "La exposición materialista de la historia lleva al pasado a colocar al presente en una situación crítica”. Esto significa, al menos, dos cosas: la teoría del conocimiento es, por necesidad histórica, crítica del progreso. A su vez, la comprensión histórica debe tomarse como evidencia póstuma de lo comprendido, esto es, de la acumulación de las ruinas que testimonian el viento arrasador del progreso. De forma implícita hemos citado el concepto de dialéctica en suspenso, fundamental para la filosofía negativa de la historia. Vale aclarar que solo las imágenes dialécticas son auténticamente históricas, ello es, no son arcaicas. En otras palabras, en la imagen lo que ha sido se une al ahora como un relámpago en una constelación. No es que lo pasado arroje luz sobre lo presente o que lo presente arroje luz sobre lo pasado, sino que en la imagen dialéctica - aquella que debe ser conquistada por la crítica-, la relación entre lo que ha sido y el ahora se expresa en su condición dialéctica; es 
decir, la imagen tiene un carácter figurativo, no temporal. Pero, por eso mismo, la naturaleza figurativa de la imagen es histórica. Así se entiende que Benjamin sostenga que todo ahora es el ahora de una determinada cognoscibilidad, de un particular modo de conocer. El crítico, aquel que desarrolla una lectura histórico-negativa del presente, lee en las imágenes sincrónicas los elementos de un pasado que, dialécticamente, se mantiene vivo en el ahora, pero que amenaza con desaparecer -por ejemplo, el que se expresa en los distintos proyectos revolucionarios que, a lo largo de la historia, han sido hundidos y declarados muertos de una vez y para siempre-. El crítico al que aludimos se diferencia del historiador de oficio que, interesado solo en la diacronía de los acontecimientos, en su arcaísmo, pasa de largo la propia presencia del pasado en el presente. Lejos está el historiador de ejercer como crítico de su propio mundo contemporáneo. De esto se colige que el hecho histórico no puede ser visto dentro de una sucesión lineal, sino como la constelación fugaz entre un acontecimiento del pasado y una situación presente. Benjamin insiste en la praxis del crítico del siguiente modo: "La imagen leída, o sea, la imagen en el ahora de la cognoscibilidad, lleva en el más alto grado la marca del momento crítico y peligroso que subyace a toda lectura" (Benjamin, 2016, p. 465). En otras palabras, la marca del momento crítico y peligroso presente en toda lectura de la historia, confirma que, a diferencia del historiador que acumula datos "ordenados" y para el cual el pasado no podrá escaparse, justo por esa indiferencia, el pasado es lo que está en riesgo de perderse.

Benjamin va más allá del diagnóstico político dentro de los términos acostumbrados. Como lo muestra la tesis $I$, la filosofía negativa de la historia es un intenso cruce de fronteras que combina materialismo y teología. Hay en ella una serie de citas secretas que exigen de sus intérpretes captar el judaísmo heterodoxo de Benjamin. Para García (2015), la teología y, en particular, el judaísmo ingresan en su filosofía como ilegales. Por ello, deben moverse borrando sus huellas. Si esta tesis es correcta, continúa García, la filosofía benjaminiana puede entenderse como una curva marrana en tanto expresión del camuflaje que en la modernidad temprana tanto como en la tardía sirve de supervivencia para los judíos. Por necesidad histórica, los marranos se convierten en expertos en el arte del disimulo; Benjamin, por su parte, ingresacon disimulo y para la exasperación de Bertolt Brecht- la teología judía dentro del materialismo histórico. En una línea de argumentación similar, Taub (2013) sostiene que los problemas teológicos del ser y el lenguaje o de la creación y la revelación, Benjamin los percibe secularizados en la filosofía y manifiestos de manera abarcadora en la historia. Recordemos el cuento de Poe El jugador de ajedrez de Maelzel. Por un lado, presenta a un autómata que siempre gana jugando ajedrez; por el otro, se encuentra un enano que, escondido dentro de la mesa de juegos, manipula al muñeco y gana las partidas. Este cuento concuerda 
completamente con la tesis no solo en su forma sino, inclusive, en su conclusión filosófica. Si para Poe no hay duda de que el espíritu mueve al muñeco, para Benjamin este espíritu -el enano- se transforma en teología. Dicho de otro modo, se trata del espíritu mesiánico sin el cual el materialismo histórico no puede triunfar. La revolución no es un proceso automático, mecánicamente guiado, sino que, al albergar su elemento teológico, ella se realiza también gracias a su propio esfuerzo mesiánico.

Como el enano giboso de la alegoría, hoy la teología solo puede actuar de manera oculta en el interior del materialismo histórico. No es más que una vieja fea, pequeña y arrugada para una época racionalista e incrédula. Podríamos decir que, al interior del materialismo histórico, guiado por la hegemonía de los partidos políticos oficiales, y por su confianza en que el progreso es la resolución de la historia humana, Benjamin introduce aquel enano teológico despreciable. Sin renunciar al materialismo, nos muestra en esta tesis $I$ la profunda necesidad de que toda noción materialista de la historia sea, a su vez, una concepción teológica, por más que los automatismos racionalizados de los partidos políticos de su momento no la hayan visto. $\mathrm{Si}$ se sigue la sugerencia de Löwy, debe entenderse que para el filósofo "[...] la teología no es una meta en sí misma, no apunta a la contemplación inefable de las verdades eternas y menos aún, como podría hacerlo suponer la etimología, a la reflexión sobre la naturaleza del Ser divino: está al servicio de la lucha de los oprimidos" (2005, p. 52).

De acuerdo con Löwy, hablar de teología en Benjamin remite a dos conceptos: la rememoración -Eigendenken- y la redención -Erlösungmesiánica. Ambos constituyen dos componentes esenciales de la filosofía negativa de la historia expresada en las tesis. En principio, situada en la esfera del individuo, la felicidad personal supone la redención del propio pasado entendido como la realización de lo que habría podido ser, pero no fue. No obstante, la tesis II pasa de la redención individual a la reparación colectiva en el terreno de la historia. Esta redención debe leerse en términos de la rememoración de los vencidos en el pasado. Esto significa que la redención mesiánica -ahora revolucionaria- exige la rememoración de los pasados frustrados. Así, la redención de la humanidad es una misión asignada por las generaciones pasadas. Esto también quiere decir que el Mesías no viene del cielo, sino que nosotros mismos disponemos de una débil fuerza mesiánica. Más aún, cada generación tiene el imperativo de ejercerla. En palabras de Benjamin: "Al igual que a cada generación anterior a la nuestra, nos fue otorgada una débil fuerza mesiánica, de la cual el pasado exige sus derechos" (2009a, p. 138). La tradición profética judía y la radicalidad de la crítica marxista se reúnen en la exigencia de una redención que, lejos de ser solo una transformación activa del presente, es también la restitución del pasado. De la tesis III se colige 
que el pasado espera de nosotros su redención; solo una humanidad redimida puede asumir íntegramente su pasado. La redención exige que el pasado sea rememorado por completo, sin diferenciar entre los acontecimientos $-\mathrm{o}$ los individuos- "grandes" y "pequeños". No podrá haber redención mientras el sufrimiento de un solo hombre sea olvidado. Como aclara Buck-Morss (2013), Benjamin advierte en el lenguaje teológico el único refugio para el desacreditado ideal de la revolución.

Si se nos permite un pequeño excurso para cerrar este acápite, vale la pena señalar que, en no pocos sentidos, la filosofía negativa de Benjamin tiene eco en la ontología negativa propuesta por Theodor Adorno (2005). Este autor plantea la necesidad de utilizar el concepto para ir en contra de la tendencia cosificadora del mismo pensamiento conceptual o, lo que es lo mismo, de su actividad identificadora, petrificante. Se trata de ir, mediante el concepto, más allá del concepto, así como de captar la constelación en la que el pasado y el presente se unen. El pensamiento conceptual implica una organización constelativa del lenguaje en la que un concepto siempre, por necesidad, se encuentra amarrado a otros. Nótese que, como consciencia de la posibilidad, la utopía es un lenguaje que sirve al pensamiento toda vez que muestra un pedazo de la existencia que, aunque de modo negativo, alcanza a lo que no es; en esta operación muestra que lo que no es, es más que lo que realmente ha llegado a ser, en la medida en que guarda las posibilidades frustradas. Por consiguiente, pensar un concepto no es solamente pensar su historia sino, por principio, el sufrimiento concentrado en la cosa de su contenido histórico-material. Aunque a veces parece animada por una cierta aristocracia del espíritu, la ontología negativa de Adorno se entiende como crítica de aquella filosofía incapaz de decir algo sobre lo que la conmueve, sobre el sentido que la compone, es decir, la ontología negativa es una crítica de la filosofía confundida con la mera palabrería (Adorno, 2003). Según el filósofo, la ambiciosa trascendencia del lenguaje desemboca fácilmente en una oquedad de sentido que se confunde con las aspiraciones del positivismo, así se asuma por encima de él. La palabrería o, según anota Adorno, la jerga de la peculiaridad -en una evidente crítica a Heidegger-, obtura el sentido, produce palabras vacías; no logra desocultar el pasado sufriente que ha sido ocultado por el concepto.

La evidente crítica del lenguaje en Adorno, una crítica ilustrada de la Ilustración (Wellmer, 1993), contiene varios elementos, entre ellos, además de ser crítica del lenguaje social y del dominio, pretende hacer visible aquello que ha sido ocultado. La crítica se mueve a partir de una lógica de la descomposición en la que la actividad dialéctico-negativa disuelve lo sólido que habita en el concepto, esto es, el mundo de las convenciones, las normas, las reglas y, en sentido amplio, de aquello que, en el proceso histórico y social, nos ha sido dado. La ontología negativa busca otorgar la palabra a lo que no es, 
a lo silenciado, pues se parte de la idea de que, pese a que a se le hayan negado las posibilidades de ser, no por ello lo silenciado carece de significado. En otras palabras, dicha ontología invoca la rememoración y la redención de la filosofía negativa de la historia.

Finalmente, como afinidad electiva, también se pueden identificar puntos de intersección entre la filosofía negativa de la historia de Benjamin y la ontología negativa de Adorno con la propuesta de Judith Butler (2006), según la cual: la crítica también debe ser entendida como una insurrección a nivel ontológico. Esta última expresión significa que podemos $-\mathrm{y}$ en muchos sentidos debemos- no estar de acuerdo con ser lo que se espera que seamos. Es decir, la crítica o la insurrección ontológica se dirigen como la tarea infinita del hombre consigo mismo. De lo que se trata es de negarse a habitar la subjetividad que se prepara para él en la modernidad. Tanto Baudelaire como Benjamin son en este sentido figuras ejemplares, se constituyen en críticos de la modernidad no solo porque hacia ella dirigen sus dardos, sino porque, en el ejercicio de encarnar la crítica, se han convertido en traidores de la clase social a la que pertenecen y esto se hace evidente en el esfuerzo por desocultar lo que los conceptos han enmascarado.

\section{La antropología negativa como crítica al universalismo antropológico formal}

Hemos dicho que para Benjamin la redención exige que el pasado sea rememorado, sin diferenciar entre los acontecimientos -0 los individuos"grandes" y "pequeños". Benjamin aspira a la redención de la humanidad entera. Todos los hombres, incluyendo los muertos, en justicia, merecen la felicidad. Esta posición "extraña” es cuestionada por Horkheimer. En una carta del 16 de marzo de 1937, escribe que los muertos, salvo que se considere la idea del "juicio final", muertos están. En otras palabras, Horkheimer apela a la historia como algo concluido y cuestiona su posible deriva teológica. Sin embargo, Benjamin (2016) responde que la historia no es solo una ciencia, también es un modo de rememoración; por lo tanto, no puede disociarse de la teología. Si la historia está concluida entonces la felicidad es imposible para los seres humanos. Por ello, la memoria no puede aceptar que la historia niegue o clausure los expedientes del sufrimiento.

Pues bien, afirmar que una condición de la redención es el rememorar el sufrimiento de la humanidad entera, implica reconsiderar el uso del concepto de universalidad. Al respecto, Mate (2009, p. 82) pregunta: “¿Qué entiende Benjamin por universalidad, esa dimensión que va unida a la racionalidad y que, por tanto, permite hablar de ética moderna y política ilustrada, es decir, de una forma de convivencia fundada en la igualdad, la libertad y la fraternidad?". Sugerir que la memoria debe ayudar a liberar todos los tipos de sufrimiento, 
incluyendo aquellos experimentados por la humanidad pasada, conlleva el hecho de que Benjamin está pensando en un concepto de universalidad que abarca la felicidad de toda la humanidad. Ahora bien, de modo evidente, las tesis contienen una crítica de ciertos modelos históricos universalistas, por un lado; pero, por el otro, también se dirigen en contra de una visión normativa de la tradición que liga en una línea de continuidad coherente la temporalidad pasada y futura (Simay, 2005). ¿Cómo es posible pues criticar o, mejor incluso, destruir el concepto de universalidad formal y, a la vez, reconstruir un tipo de universalidad que no sea ajena a lo "pequeño", a las heridas infringidas a las formas de vida que no importan en el relato triunfalista de los vencedores? ¿Cómo es posible redimir a los vencidos? Para Mate (2009), la propuesta Benjamin tiene que ver con realizar una universalidad realmente universal. Dicho de otro modo, las tesis señalan la necesidad -no solo lógica sino, sobre todo, ética, ontológica e incluso antropológica- de integrar en la universalidad lo "pequeño" y lo excluido por la -falsa- universalidad histórica y cultural de la sociedad occidental devota de lo "grande".

De aquí se sigue que, inseparable del de rememoración, el concepto de redención, entendido como el retorno de todas las cosas a su estado originario, contiene en sí mismo un carácter universal. Vayamos por partes. Para Albertini (2005), Benjamin sigue de cerca el desarrollo del concepto propuesto por Franz Rosenzweig; en particular, tal como aparece en La estrella de la redención. Rosenzweig se distancia de la filosofía hegeliana en 1910. Para él, en la filosofía de la historia de Hegel, el individuo es reducido a una especie de ficha anónima sometida dentro de un juego de ajedrez. Según las leyes del juego, el todo es la superación de las partes; esto no pocas veces implica que en el proceso las partes sean sacrificadas. A este proceso declarado violento, Rosenzweig opone la revelación -revelatio- que despierta al hombre a su realidad efectiva como individuo. Empero, la redención no lo es de un individuo único sino de el "hablar común" de la humanidad entera. Es histórica y esto significa que todavía no está completa o terminada. En este sentido, se entiende como una utopía que se actualiza de instante en instante porque puede ocurrir en cualquiera de ellos. Como informa Albertini, tanto para Rosenzweig como para Benjamin, la rememoración del pasado anticipa la redención futura en tanto vigencia de que el hombre debe realizar - consumar- la idea de una humanidad libre, sin menoscabo de ninguna vida. Tal vez por ello Löwy (1997) dirá que Benjamin es uno de esos extraños autores que captan la afinidad electiva entre el mesianismo judío y la utopía libertaria, dando forma a un nuevo pensamiento extemporáneo y, por lo tanto, siempre actual -en esta misma categoría tenemos que considerar la filosofía de Rosenzweig-.

El sufrimiento de toda la humanidad nos obliga en términos morales, políticos e históricos; por esto el deber del crítico es rememorar y redimir todas 
las formas de vida pasadas -y actuales- a las que se les ha negado la felicidad y su realización afortunada. El de Benjamin es un materialismo histórico que amplía el de Marx (1980). Si el materialismo histórico clásico nos ha dicho que la humanidad es algo así como una estructura común que se expresa en la totalidad de las relaciones sociales; y si, en consecuencia, la enajenación de los hombres tiene que ver con el hecho de que se encuentran (auto)extrañados en esta estructura común -por ello son incapaces de comprender que la humanidad no es una idea encarnada, por así decir, en los individuos-, entonces el de Benjamin es un materialismo histórico que radicaliza las premisas del compromiso político y de la trasformación revolucionaria de los medios de vida, ya sugeridas por el autor de El capital, al convocar las fuerzas vitales que permitan al hombre ir a la cosa misma, esto es, ir hacia las condiciones históricas y materiales naturalizadas que actúan en el presente ruinoso de la humanidad y que hundieron las posibilidades de una vida lograda para los hombres en el pasado.

Sumado a lo anterior, centrando su mirada revolucionaria en el pasado, y ampliando el concepto de universalidad por mor de su preocupación extendida hacia todas las formas de vida humana, Benjamin introduce un giro antropológico singular en el pensamiento histórico materialista. Permítasenos aclarar esta afirmación. Como podrá advertirse, su recurso no es a la antropología filosófica, ni contribuye a su fortalecimiento. Al contrario, si se nota bien, la hace imposible. Para Benjamin el hombre no es un ser inacabado que busca realizarse, recabando en ideales disponibles para darse forma. Al contrario, la negatividad de Benjamin plantea que el hombre solo puede hallarse en el desecho. La aspiración a formarlo conforme a ideales de perfección, si se percibe bien el curso amargo de la historia, ha contribuido más a su ruina que a la felicidad. Por ello, la universalidad de lo humano no es la realización de un ideal específico de hombre que debe alcanzarse a través de la formación Bildung-. El humanismo real al que Benjamin (2010b) se refiere, en realidad, es la destrucción de todo ideal antropológico, lo que incluye la idealidad de la formación (Piñeres Sus, 2016; Hincapié García, 2019).

A manera de ilustración, a través de la Conquista de América, Mate (2013) plantea esta nueva concepción de universalidad benjaminiana, al exponer las aporías de la sociedad occidental en su búsqueda de expandir universalmente sus propios valores y su economía. La Conquista es una desposesión ontológica y antropológica que opera mediante la implantación de un tipo de hombre como ideal antropológico. El fracaso del proyecto civilizador, o tal vez su propio éxito - como quiera que se juzgue-, radica en que Europa vive con la pretensión de una universalidad que no realiza ${ }^{7}$. Para la mentalidad occidental dominante,

${ }^{7}$ Esta ceguera histórica, para muchos ya superada, reaparece toda vez que se actualiza la aspiración reaccionaria de que Europa sea la consciencia moral del mundo. Nótese un trabajo reciente 
los pueblos (post)coloniales se mantienen a sí mismos en una condición de simples determinaciones particulares y aisladas, que, ya sea por su incapacidad constitutiva o por su voluntad débil, no han podido salir de su estado de atraso histórico. Díaz Serrano (2010) sostiene que la Conquista económica, política y espiritual de América, por ejemplo, exige que el horror dejado a su paso se convierta en fe. "Así, la imperfección de la conversión americana fue en realidad la manifestación de la dinámica de dominación de la Monarquía Hispánica, heterogénea y cambiante, a pesar de su suscripción al ideal de la universalización" (Díaz Serrano, 2010, p. 98).

Expuesto de este modo, la Conquista de América funge como el contraejemplo del fracaso de la universalidad de la sociedad occidental: "ininguna forma de humanidad distinta a la nuestra!" proclama el yo europeo en el afán de elevar a universales sus propias formas de vida. La historia ejemplar de la Conquista de América (Todorov, 2005) hace visible el fracaso de toda relación colonial. El énfasis unilateral del descubrimiento se verifica en la formación del yo del colonizador, incapaz de descubrirse en la alteridad. Su propia teoría acerca del Otro sugiere, en principio, un doble movimiento que, después, va a dar en la negación absoluta de la humanidad del colonizado: o bien piensa en el otro -en ese caso en el indio del nuevo mundo- como un ser humano idéntico, y por tanto proyecta sus propios valores sobre él mientras le exige que los asimile; o bien lo trata inmediatamente como inferior, negando no solo su diferencia sino, peor aún, sustrayendo su humanidad. En ambos movimientos la humanidad del indio es negada. En el primero, porque solo se reconoce su existencia formal, siempre y cuando abandone a los suyos y asuma como propios los valores europeos; en el segundo, porque es percibido de forma inmediata como un ser inferior, cuya existencia vacila entre lo humano y lo animal. Antes de Todorov, Albert Memmi (1969) observa que el colonizador elabora copiosas representaciones degradadas de los colonizados porque solamente de ese modo sus acciones escandalosas pueden pasar inadvertidas. La aparente reconciliación del yo europeo y del yo colonial solo se realiza en una universalidad antropológica formal, carente de realidad sustantiva; como diría Benjamin, se hunde en su propia ruina moral al no reconocer el valor de los proyectos frustrados y el derecho a la felicidad de los vencidos.

Mate (2013) capta muy bien la deuda histórica de Europa no solo con los judíos -desde la expulsión en 1492 hasta su aniquilación en los campos de concentración y de exterminio-, sino también con los pueblos (pos)coloniales. A pesar de que su propuesta es incisiva, la interpretación del singular giro

de Fernández Liesa (2020, p. 28), donde se sostiene, sin reparo y con candor, que, a través de los derechos humanos, Europa no solo debe iluminarse a sí misma, también debe "recuperar su rol de faro humanista que ilumina al resto del mundo". No deben pasar desapercibidas las metáforas de faro y resto, puesto que caen en la esfera de lo que Adorno denomina la jerga de la peculiaridad al servicio del ocultamiento de los pasados ruinosos.

Araucaria. Revista Iberoamericana de Filosofia, Politica, Humanidades y Relaciones Internacionales, año $23, \mathrm{n}^{\circ} 48$. Tercer cuatrimestre de 2021. Pp. 57-77. ISSN 1575-6823 e-ISSN 2340-2199 https://dx.doi.org/10.12795/araucaria.2021.i48.03 
antropológico que lee en Benjamin puede ampliarse. Como se ha dicho, plantea relaciones finas entre universalidad y redención del sufrimiento humano. Con el propósito de comprender la novedad que, como en el caso de la praxis del cronista descrito en la tesis III, se encuentra en una concepción de universalidad que tiene en cuenta lo "grande" y lo "pequeño", Mate revisa la diferencia entre las figuras del proletariado, contemplada en la tradición marxista, y la del pobre, que aparece en la tradición bíblico-teológica. Sin embargo, y sin desconocer la claridad analítica de su argumento, abandona muy rápido su planteamiento en torno a las relaciones entre la universalidad formal y el contenido antropológico ideal que impone. Verbigracia, desoculta las consecuencias de que el Espíritu del mundo hegeliano tiene su centro en Europa; no siendo suficiente, se da cuenta de que, para Hegel, como para otros pensadores modernos, el destino de América es su occidentalización o bien su exclusión de la universalidad, mediante su fijación en la pre-historia. Pero, no avanza su argumento hasta plantear la necesidad de disolver cualquier ideal antropológico.

El concepto de universalidad que extraemos de Benjamin nos dice que, sin importar las diferencias que la historia ha introducido entre los hombres, incluyendo las creencias religiosas, todos comparten una común humanidad, no como seres inacabados -según dirá la antropología filosófica-, sino porque es justa la aspiración de todos a dar forma a una vida lograda. Hasta el menos visible de los hombres participa de la comunidad humana ampliada; preciso por ello su sufrimiento debe importar tanto como el de los otros. Incluso el sufrimiento del vencido es más importante para la praxis materialista de la historia al considerar su dimensión moral. Si los vencedores heredan intacta su tradición y sus formas de vida -incluyendo la aspiración a recuperar el rol de faro del resto del mundo-, nuestro deber de memoria se dirige a la rememoración de los vencidos, pues su tradición es la que siempre está en riesgo de desaparecer ${ }^{8}$. Esto también supone que si nuestro compromiso es moralmente normativo y universal, preciso por ello debemos rechazar todo concepto prescriptivo en torno a la pregunta qué es el hombre y la aspiración a convertirse en el faro que ilumina la respuesta.

Esta última sería precisamente la propuesta de una antropología negativa benjaminiana; se trata de una mirada crítica incapaz de comprometerse con algún concepto sobre aquello que debe ser lo humano, pues comprende que, en un compromiso tal, la humanidad es obligada a ser aquello que se señala como un tipo de existencia correcta para ella. Así como la universalidad corregida

\footnotetext{
8 De hecho, no podemos aceptar esa división maniquea entre vidas "grandes" y "pequeñas" promulgada por las distintas formas de humanismo y de esencialismo antropológico. Tampoco el ejercicio político contemporáneo que denuncia ciertos tipos de violencia, por ejemplo, la violencia racial o la de género, guardando silencio frente al servicio militar obligatorio, la violencia de Estado o frente a la violencia del capitalismo. Butler (2010) cuestiona los movimientos sociales que negocian privilegios con la figura del Estado sin entrar a cuestionar la inevitabilidad con la que este se presenta como el arbitrio moralmente más alto de las relaciones sociales.
} 
hace a un lado las ficciones que separan la historia en acontecimientos -o individuos- "grandes" y "pequeños", la antropología negativa descarta no solo los conceptos prescriptivos sobre lo que debe ser lo humano, sino la consiguiente división de los hombres y las comunidades entre más y menos cercanos a un ideal de humanidad.

\section{Conclusiones}

Enfrentamos dos tipos de universalidad. La universalidad de los vencedores, y sus tradiciones continuamente actualizadas, junto con las teorías filosóficas e históricas que sirven para fundamentar la concepción de un tiempo lineal, homogéneo y vacío cuyo télos es el progreso, caracterizada por Mate (2009, p. 90) - glosando a Benjamin- como una universalidad “(...) reaccionaria porque utiliza todos los medios para imponerse a los demás, en nombre de su pretendido interés universal". Se trata también de una universalidad totalitaria incapaz de reconocer las diferencias pues, por su propia constitución, sacrifica el destino individual apelando a supuestos bienes comunes y universales. De manera paradójica, esta universalidad excluye las formas particulares de existencia. Dicho de otro modo, este tipo de universalidad se afinca en el principio de reconstrucción, esto es, la empatía entre el pasado y el presente promovida por aquellas interpretaciones de la historia que, ya sean de inspiración filosófica o propiamente historiográfica, solo se fían reaccionariamente de las tradiciones que vinculan todo presente con el pasado para transformarlo en una herencia que restaura la dominación.

Por su parte, el tipo de universalidad propuesto por Benjamin se encuentra muy lejos de ser reaccionario. Gracias a su principio constructivo, aquí la universalidad es capaz de ver al todo en cada una de las partes. Ningún tipo de universalidad puede valer si tiene como costo la felicidad, así sea la de un solo individuo. Mate es enfático en que, en oposición a sus versiones ilustradas, la verdadera historia universal valora como absoluto la vida de la humanidad entera y exige hasta el reconocimiento de la injusticia pasada cometida en contra del más "insignificante" de los hombres. En últimas, la antropología negativa que derivamos de Benjamin, moralmente tiene que oponerse a la universalidad antropológica formal puesto que, al excluir las formas de vida de los vencidos, eleva las de los vencedores como los ideales desde donde se juzga el resto de la humanidad. Asimismo, esta antropología negativa, en términos políticos, rechaza cualquier forma de amnistía histórica donde el pasado se declara ya superado, sin ningún esfuerzo real por reparar el sufrimiento de los vencidos.

Llegados hasta aquí, cabe señalar que en 1969 se publica el importante libro de Ulrich Sonnemann, titulado: Negative Anthropologie. Sonneman 
(1969), entiende por antropología negativa un programa sistemático de investigación que cuestiona cualquier asunción determinista sobre lo que define el ser o el deber ser de lo humano. La antropología negativa no desconoce que se desarrollan investigaciones sobre los seres humanos que indagan en sus constantes antropológicas; sin embargo, Sonnemann sostiene que de esto no puede deducirse ningún universal que aclare qué es el hombre. Antropología negativa significa que lo humano es pura negación y ausencia. Esto puede significar que de los seres humanos puede saberse solo en la negación del universalismo formal antropológico y a través de lo que ha sido dejado por fuera de dicho universal. Como puede percibirse, la perspectiva de Sonnemann es consonante con la de Benjamin, puesto que, para reiterar, la antropología negativa benjaminiana se entiende como el rechazo a toda forma de menoscabo de las diferencias entre los hombres; es un esfuerzo por radicalizar la crítica de las antropologías normativas y de los intentos por justificar, en nombre del progreso o de la armonía entre los pueblos, amnistías para los pasados nunca redimidos. En otras palabras, de la antropología negativa benjaminiana se infiere que la imposición de una universalidad antropológica formal es opuesta a la praxis crítica del materialismo antropológico en el que resuena el eco de Marx y los profetas.

\section{Bibliografía}

Adorno, Theodor. (2003). El ensayo como forma. En Obra completa 11. Notas sobre literatura. Madrid: Akal, pp. 11-34.

Adorno, Theodor. (2005). Dialéctica negativa. Obra completa 6. Madrid: Akal. Albertini, Francesca. (2005). Historia, redención y mesianismo. En F. Rosenzweig (Aut.). El nuevo pensamiento, 127-162. Buenos Aires: Adriana Hidalgo, pp. 127-162.

Benjamin, Walter. (1974). Über einige Motive bei Baudelaire. En Gesammelte Schriften I-I. Frankfurt am Main: Suhrkamp, pp. 605-653

Benjamin, Walter. (2001). Sobre algunos temas en Baudelaire. En Ensayos escogidos. México: Ediciones Coyoacán, pp. 7-41.

Benjamin, Walter. (2009a). Sobre el concepto de historia. En Estética y política, 135-158. Madrid: Akal, pp. 459-490.Buenos Aires: Las Cuarenta, pp. 135158.

Benjamin, Walter. (2010a). Sobre el programa de la filosofía venidera. En Obras. Libro II/vol. 1. Madrid: Abada, pp. 162-175.

Benjamin, Walter. (2010b). Karl Kraus. En Obras. Libro II/vol. 1. Madrid: Abada, pp. 341-376. 
Benjamin, Walter. (2011). El narrador. En Iluminaciones IV. Para una crítica de la violencia y otros ensayos. Uruguay: Aguilar, 2011, pp. 125-152.

Benjamin, Walter. (2016). Libro de los pasajes. Madrid: Akal.

Buck-Morss, Susan. (2001). Dialéctica de la mirada. Walter Benjamin y el proyecto de los pasajes. Madrid: La balsa de Medusa.

Buck-Morss, Susan. (2013). Origen de la dialéctica negativa. Theodor W. Adorno, Walter Benjamin y el Instituto de Frankfurt. Argentina: Eterna Cadencia.

Bergson, Henri. (1949). Matière et mémoire. Paris: Presses Universitaires de France.

Butler, Judith. (2006). Vida precaria. El poder del duelo y la violencia. Buenos Aires: Paidós.

Butler, Judith. (2010). Violencia de Estado, guerra, resistencia. Por una nueva política de la izquierda. Buenos Aires: Katz.

Díaz Serrano, Ana. (2010). Políticas de la conversión. Memoria, testimonio y materialidad de la hispanización en la Nueva España (siglo XVI). Arancaria. Revista Iberoamericana de Filosofía, Política, Humanidades y Relaciones Internacionales, año 12, n. 24, pp. 79-98.

Fernández Liesa, Carlos. (2020). Reconquistar los derechos humanos por la Unión Europea. Araucaria. Revista Iberoamericana de Filosofía, Política, Humanidades y Relaciones internacionales, año 22, n. 45, pp. 27-50.

García, Luis Ignacio. (2015). Walter Benjamin: la curva marrana. En A. Sucasas y E. Taub (Eds.). Pensamiento judio contemporáneo. Buenos Aires: Lilmod - Prometeo, pp. 29-272.

Hincapié García, Alexánder. (2019). La violencia educadora de Walter Benjamin. En A. Hincapié y E. Taub (Eds.). De Benjamin a Marcuse. Lecturas en torno a Para una crítica de la violencia de Walter Benjamin. Medellín: Editorial Bonaventuriana, pp. 133-151.

Kafka, Franz. (2018). Cartas. 1900-1914. Barcelona: Galaxia Gutemberg.

Löwy, Michael. (1997). Redención y utopía. El judaísmo libertario en Europa central. Un estudio de afinidad electiva. Buenos Aires: El cielo por asalto.

Löwy, Michael. (2005). Walter Benjamin: aviso de incendio. Buenos Aires: Fondo de Cultura Económica.

Marx, Karl. (1980). Manuscritos: economía y filosofía. Madrid: Alianza.

Mate, Manuel Reyes. (2009), Medianoche en la historia. Comentarios a las tesis de Walter Benjamin "Sobre el concepto de historia". Madrid: Trotta.

Mate, Manuel Reyes. (2013). La piedra desechada. Madrid; Trotta.

Memmi, Albert. (1969). Retrato del colonizado precedido por retrato del colonizador. Buenos Aires: Ediciones de la flor.

Molano, Mario Alejandro. (2014). Walter Benjamin: historia, experiencia y modernidad. Ideas y Valores, vol. 63, n. 154, pp. 165-190. 
Piñeres Sus, Juan David (2016). Antropología e idealidad. Algunas reflexiones sobre crueldad y superfluidad. En B. Escobar y A. Hincapié (Comp.). Modernidad y política. Sobre la pregunta antropológica. Medellín: Unaula, pp. 19-42.

Simay, Philippe. (2005). Tradition as injunction: Benjamin and the critique of historicisms. En A. Benjamin (Ed.). Walter Benjamin and History. New York: Continuum, pp. 137-155.

Sonnemann, Ulrich. (1969). Negative Anthropologie. Vorstudien zur Sabotage des Schicksals. Hamburg: Rowohlt.

Taub, Emmanuel. (2013). Mesianismo y redención. Prolegómenos para una teología política judía. Argentina: Miño Dávila.

Todorov, Tzvetan. (2005). El descubrimiento de América. El problema del otro. México: Siglo XXI.

Wellmer, Albrecht. (1993). Sobre la dialéctica de modernidad y posmodernidad. La crítica de la razón después de Adorno. Madrid: Editorial Visor. 
